Imagem

\title{
Abordagem Endovascular na Oclusão Ilíaca com Sofrimento Isquêmico Agudo do Membro Inferior: Procedimento Simples e Efetivo em Pacientes de Alto Risco
}

\author{
Rogério Sarmento-Leite, Nilo Mandelli, Mario Frederico C. Pereira, Carlos A.M. Gottschall \\ Porto Alegre, RS
}

A doença vascular periférica cujos fatores de risco são bem conhecidos, apresenta alta prevalência, podendo determinar grande limitação física e, muitas vezes, a perda do membro acometido. Sua apresentação clínica pode ser insidiosa e os sintomas se manifestarem de forma lenta e progressiva, determinando claudicação e lesões tróficas. Outras vezes, entretanto, se manifestam de maneira aguda com importante repercussão clínica, determinada por isquemia, dor, incapacitação funcional e possibilidade de quadros toxêmicos associados. A intervenção precoce é determinada pela gravidade do caso, sendo a arteriografia o método mais difundido e considerado padrão-ouro diagnóstico. Os recentes avanços na técnica e no material utilizado na área endovascular com a formação de equipes multidisciplinares têm aumentado em muito o espectro de atuação intervencionista, permitindo às técnicas minimamente invasivas, a realização de procedimentos terapêuticos, eficazes, resolutivos e, até salvadores, em pacientes cuja morbimortalidade cirúrgica seria muito alta. Um homem de 82 anos com história de cardiopatia isquêmica grave, diabetes mellitus e doença vascular periférica iniciou subitamente, dor no membro inferior esquerdo, associada à perda de pulso, palidez e queda na temperatura. Foi realizada angiografia de urgência com aproximadamente $36 \mathrm{~h}$ de evolução do quadro que mostrou oclusão total da artéria ilíaca comum esquerda (fig. 1). Optou-se por abordagem terapêutica percutânea com acesso arterial bilateral (fig. 2) com implante de stent Express LD $9.0 \times 57$ mm (Boston Scientific Maple Growe, MN-USA) na ilíaca comum esquerda e angioplastia da ilíaca contra-lateral com balão Power Flex 7.0 x 20mm (Crodis corporation, Miami, FL-USA) para evitar deslocamento de placa (fenômeno de snow-plow). Houve recuperação total do calibre e fluxo do vaso com restauração da circulação anterógrada para o membro inferior esquerdo (fig. 3). Em função da grande presença de trombos, optou-se por manter o paciente com anticoagulação a pleno estendida por pelo menos 6 meses com cumarínicos. 0 paciente apresentou alívio sintomático tendo tido alta hospitalar deambulando, sem outras queixas.

Instituto de Cardiologia do Rio Grande do Sul/Fundação Universitária de Cardiologia

Endereço para Correspondência: Rogério Sarmento-Leite

Av. Princesa Isabel, 370 - Hemodinâmica - Cep 90620-001

Porto Alegre - RS - E-mail: sleite.pesquisa@cardiologia.org.br Recebido para Publicação em 10/12/2003

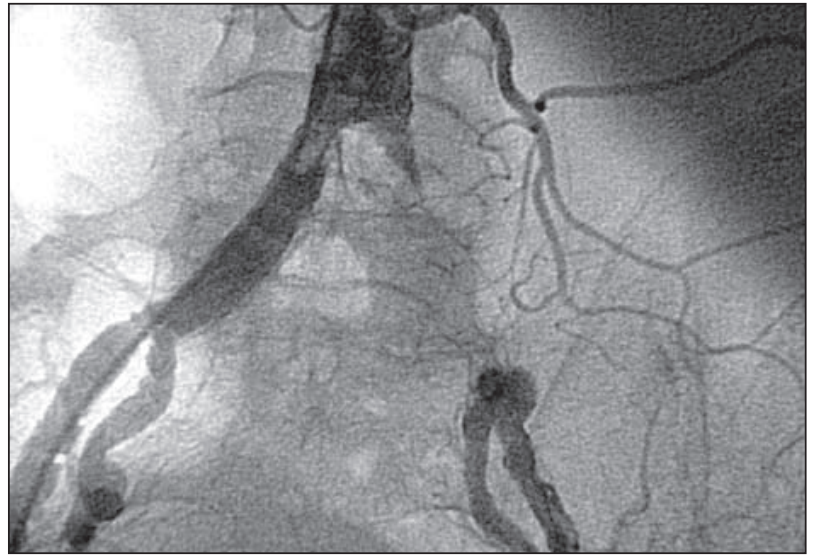

Fig. 1 - Arteriografia aorto-ilíaca demonstrando oclusão total da artéria ilíaca comum esquerda.

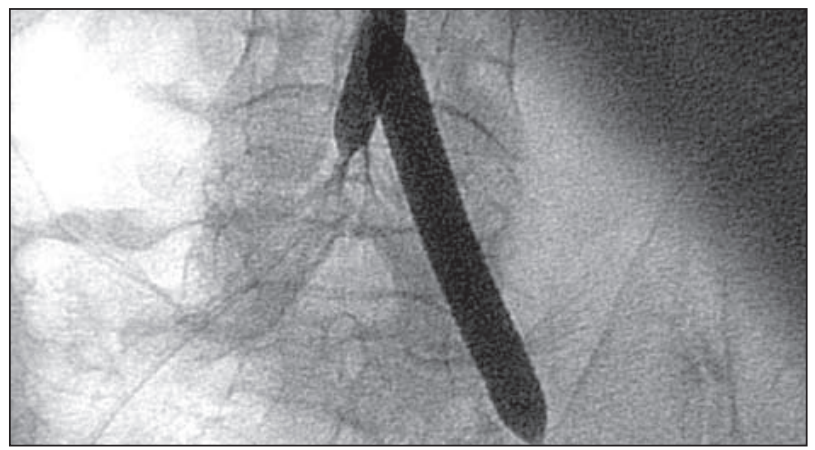

Fig. 2 - Abordagem terapêutica percutânea com acesso arterial bilaterial com implante de stent na artéria ilíaca comum esquerda e angioplastia da ilíaca contra-lateral para evitar descolamento da placa.

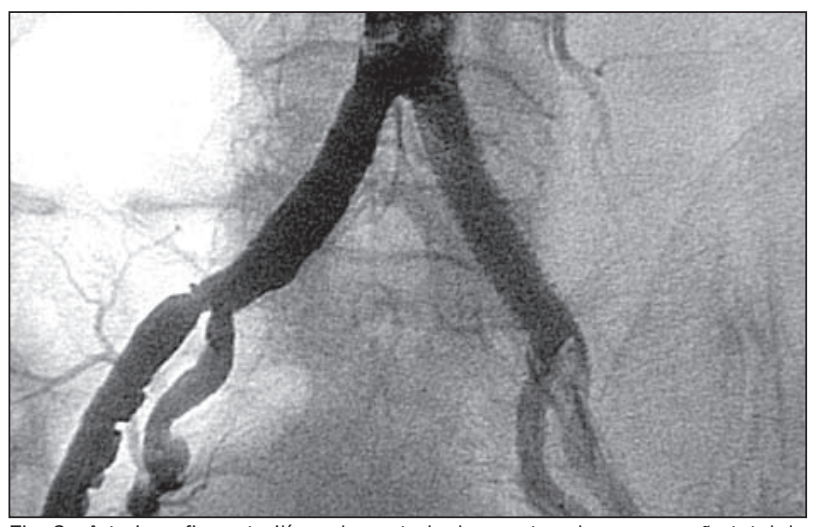

Fig. 3 - Arteriografia aorto-ilíaca de controle demonstrando recuperação total do calibre e fluxo do vaso, com restauração da circulação anterógrada para o membro inferior esquerdo. 